\title{
Synthesis of $\mathrm{Cog}_{9} \mathrm{~S}_{8}$ and $\mathrm{CoS}$ nanocrystallites using $\mathrm{Co}$ (II) thiosemicarbazone complexes as single-source precursors
}

\author{
AMOL S PAWAR and SHIVRAM S GARJE* \\ Department of Chemistry, University of Mumbai, Vidyanagari, Santacruz (East), Mumbai 400 098, India
}

MS received 20 June 2015; accepted 30 July 2015

\begin{abstract}
Cubic $\mathrm{Cog}_{8} \mathrm{~S}_{8}$ and hexagonal $\mathrm{CoS}$ nanocrystallites were prepared by pyrolysis and solvothermal decomposition methods using $\mathrm{Co}(\mathrm{LH})_{2} \mathrm{Cl}_{2}$ and $\mathrm{CoL}_{2}$ (where $\mathrm{LH}=$ thiosemicarbazones of furfuraldehyde, cinnamaldehyde and 4-fluoro-acetophenone) as single-source precursors. These nanocrystallites were characterized by powder X-ray diffraction, scanning electron microscopy, transmission electron microscopy (TEM), selected area electron diffraction, UV-Vis, PL and Raman spectroscopic techniques. From TEM images, the average grain size of asprepared cobalt sulphide nanocrystallites was found to be 7-10 $\mathrm{nm}$. Depending on experimental conditions, various morphologies such as spherical, pyramidal, hollow spheres, etc. are observed in the TEM images.
\end{abstract}

Keywords. Cobalt sulphide; single-source precursors; pyrolysis and solvothermal decomposition.

\section{Introduction}

Nanomaterials have attracted a great attention of the researchers due to their interesting chemical and physical properties and potential technological applications. ${ }^{1-7}$ Transition metal sulphide nanostructures have wide applications. Among these materials, cobalt sulphides are especially important because the Co-S bonds present in them have several forces and binding mechanisms that can form ionic bonds, covalent bonds and metallic bonds in molecule. ${ }^{8}$ Cobalt sulphide exists in several phases, such as $\mathrm{Co}_{4} \mathrm{~S}_{3}$, $\mathrm{Co}_{9} \mathrm{~S}_{8}, \mathrm{CoS}, \mathrm{Co}_{1-X} \mathrm{~S}, \mathrm{Co}_{3} \mathrm{~S}_{4}, \mathrm{Co}_{2} \mathrm{~S}_{3}$ and $\mathrm{CoS}_{2} .{ }^{9,10}$ These are important materials due to their use as hydrosulphurization catalyst in magnetic devices. ${ }^{11,12}$ Cobalt sulphide $(\mathrm{CoS})$ is a semiconductor with bandgap of $0.9 \mathrm{eV}$, whereas, $\mathrm{Co}_{3} \mathrm{~S}_{4}$ has optical bandgap of about $0.78 \mathrm{eV}$. Electrical resistivity of CoS is of the order $10^{-10} \Omega \mathrm{cm} .{ }^{13}$ Cobalt disulphide is metallic solid, which displays ferromagnetic properties with Curie temperature of about $120 \mathrm{~K} .{ }^{14}$ In the recent years cobalt sulphide has been used in many applications such as solar energy absorber ${ }^{15}$ in ultra-density magnetic recording, ${ }^{16}$ as anodes for Li-ion batteries ${ }^{17}$ and catalysts for hydrosulphurization or dehydroaromatization. ${ }^{18,19}$

Various methods have been adopted to prepare these types of materials. This includes arc discharge evaporation, ${ }^{20}$ chemical vapour deposition, ${ }^{21}$ template confined growth, ${ }^{22,23}$ hydrothermal processing, ${ }^{24,25}$ etc. However, the preparation of $\mathrm{CoS}$ and $\mathrm{Co}_{9} \mathrm{~S}_{8}$ using single-source precursor has not been much explored. In view of inherent advantages of single-source precursors, such as low toxicity, control over stoichiometries, limited pre-reactions etc., we thought it

\footnotetext{
*Author for correspondence (ssgarje@ chem.mu.ac.in, ssgarje@yahoo.com)
}

worthwhile to explore the possibility of use of cobalt thiosemicarbazone complexes as single-source precursors to get these materials. It is found that the thermal and solvothermal decomposition of thiosemicarbazone complexes of the type $\mathrm{CoL}_{2}$ and $\mathrm{Co}(\mathrm{LH})_{2} \mathrm{Cl}_{2}$ (where $\mathrm{LH}=$ thiosemicarbazone of furfuraldehyde (furtsczH), cinnamaldehyde (cinnamtsczH) and 4-fluoroacetophenone (4-f-acphtsczH)) results into the formation of $\mathrm{CoS}$ or $\mathrm{Co}_{9} \mathrm{~S}_{8}$ nanocrystallites (tables 1 and 2).

\section{Experimental}

\subsection{Instrumentation}

Elemental analyses $(\mathrm{C}, \mathrm{H}, \mathrm{N}, \mathrm{S})$ of all the compounds were carried out using Thermo Finnigan, Italy, Model FLASH EA 1112 Series, elemental analyzer. Infrared spectra of complexes were recorded using Perkin Elmer Spectrum One FTIR Spectrometer in $4000-400 \mathrm{~cm}^{-1}$ range. The molar conductance of the complexes of the solutions in dimethylformamide $\left(10^{-3} \mathrm{~mol}^{-1}\right)$ at room temperature was measured using Toshniwal conductivity meter. The TGA was carried out using Perkin Elmer Instrument, Pyris Diamond TG/DTA model, with heating rate of $10^{\circ} \mathrm{C} \mathrm{min}^{-1}$ under nitrogen atmosphere. XRD studies were carried out using $\mathrm{CuK} \alpha$ radiation on an Xpert PRO Analytical X-ray Diffractometer. SEM images were recorded on a FEI Quanta-200 scanning electron microscope at an accelerating voltage of $20 \mathrm{kV}$. EDS was performed with a spectroscope attached to SEM. Transmission electron microscopy (TEM) measurement and energy dispersive analysis by X-ray (EDAX) were recorded on a PHILIPS CM 200 microscope with operating voltages between 20 and $200 \mathrm{kV}$. The electronic spectra were recorded on a UV-2450 PC Shimadzu spectrometer in $800-200 \mathrm{~nm}$ 
Table 1. Pyrolysis of $\mathrm{CoL}_{2}$ and $\mathrm{CoCl}_{2}(\mathrm{LH})_{2}$ complexes.

\begin{tabular}{|c|c|c|c|}
\hline Precursors & Temperature $\left({ }^{\circ} \mathrm{C}\right)$ & $\begin{array}{l}\text { Crystalline } \\
\text { phase }\end{array}$ & $\operatorname{EDAX}(\mathrm{Co}: \mathrm{S})$ \\
\hline $\mathrm{Co}(\text { furtscz })_{2}$ & 450 & Hexagonal CoS (JCPDS: 75-0605) & $46.15: 53.85$ \\
\hline $\mathrm{CoCl}_{2}$ (furtsczH $)_{2}$ & 475 & Cubic $\mathrm{Co}_{9} \mathrm{~S}_{8}$ (JCPDS: 75-2023) & 48.48:51.52 \\
\hline $\mathrm{Co}(\text { cinnamtscz })_{2}$ & 425 & Hexagonal CoS (JCPDS: 75-0605) & $54.58: 45.42$ \\
\hline $\mathrm{CoCl}_{2}(\text { cinnamtsczH })_{2}$ & 500 & Cubic $\mathrm{Cog}_{9} \mathrm{~S}_{8}$ (JCPDS: 75-2023) & $61.41: 38.59$ \\
\hline $\mathrm{Co}(4-\mathrm{f}-\mathrm{acphtscz})_{2}$ & 475 & Cubic $\mathrm{Co}_{9} \mathrm{~S}_{8}$ (JCPDS: 75-2023) & $57.82: 42.18$ \\
\hline $\mathrm{CoCl}_{2}(4-\mathrm{f} \text {-acphtsczH })_{2}$ & 475 & Cubic $\mathrm{Co}_{9} \mathrm{~S}_{8}$ (JCPDS: 75-2023) & $51.05: 48.95$ \\
\hline
\end{tabular}

Table 2. Solvothermal decomposition of $\mathrm{CoL}_{2}$ and $\mathrm{CoCl}_{2}(\mathrm{LH})_{2}$ complexes in ethylene glycol.

\begin{tabular}{lcc}
\hline Precursors & \multicolumn{1}{c}{ Crystalline phase } & EDAX (Co:S) \\
\hline $\mathrm{Co}(\text { furtscz })_{2}$ & Cubic Cog S $_{8}$ (JCPDS: 75-2023) & $47.52: 52.48$ \\
$\mathrm{CoCl}_{2}(\text { furtsczH })_{2}$ & Hexagonal CoS (JCPDS: 75-0605) & $47.17: 52.83$ \\
${\mathrm{Co}\left(\mathrm{cinnamtscz}_{2}\right.}_{\mathrm{CoCl}_{2}(\text { cinnamtsczH })_{2}}$ & Hexagonal CoS (JCPDS: 75-0605) & $45.47: 54.53$ \\
$\mathrm{Co}(4-\mathrm{f}-\mathrm{acphtscz})_{2}$ & Hexagonal CoS (JCPDS: 75-0605) & $49.97: 50.03$ \\
$\mathrm{CoCl}_{2}(4-\mathrm{f}-\mathrm{acphtsczH})_{2}$ & Hexagonal CoS (JCPDS: 75-0605) & $54.00: 46.00$ \\
\hline
\end{tabular}

range. Raman spectra were recorded on RENISHAW inVia Raman Microscope using $514 \mathrm{~nm}$ Argon ion laser in the range of $100-1200 \mathrm{~cm}^{-1}$.

\subsection{Preparation of complexes}

The precursors were prepared as described below:

2.2a Preparation of $\mathrm{Co}(\text { furtscz })_{2}$ (1): $\mathrm{Co}(\mathrm{acac})_{2} \cdot 4 \mathrm{H}_{2} \mathrm{O}$ (0.7687 g, $3.08 \mathrm{mmol}$ ) was dissolved in $15 \mathrm{ml}$ dry methanol. To this, $1.0533 \mathrm{~g}(6.22 \mathrm{mmol})$ of furfuraldehyde thiosemicarbazone dissolved in $10 \mathrm{ml}$ dry methanol was added with constant stirring and the reaction mixture was refluxed for $8 \mathrm{~h}$. Then it was cooled to room temperature and the solvent was evaporated under vacuum. The resulting brown solid was repeatedly washed with cyclohexane and n-hexane. The product obtained was dried in vacuo and weighed (yield: 1.032 g, 84.62\%, M.P. $196^{\circ} \mathrm{C}$ ). Elemental analyses for $\mathrm{CoC}_{12} \mathrm{H}_{12} \mathrm{~N}_{6} \mathrm{~S}_{2} \mathrm{O}_{2}$, \% found (calcd): Co 15.29 (14.91), C 36.81 (36.44), H 3.40 (3.03), N 21.73 (21.25), S 16.55 (16.19); IR: $3427 \mathrm{~cm}^{-1}, 3332 \mathrm{~cm}^{-1}$ ( $v_{\mathrm{NH} 2}$ asym. and sym.), $1585 \mathrm{~cm}^{-1}\left(v_{\mathrm{C}-\mathrm{N}}\right), 1013 \mathrm{~cm}^{-1}\left(v_{\mathrm{C}-\mathrm{S}}\right) ; \mathrm{NMR}(\delta$ in $\mathrm{ppm})$ ${ }^{1} \mathrm{H}: 6.54-8.43\left(\mathrm{~m}, \mathrm{NH}_{2}+\mathrm{C}_{4} \mathrm{H}_{3}\right),{ }^{13} \mathrm{C}: 178.66(\mathrm{C}=\mathrm{S}), 149.30$ $(\mathrm{CH}=\mathrm{N}), 144.66,135.61,118.98,113.30$ (aromatic carbons).

2.2b Preparation of $\mathrm{CoCl}_{2}$ (furtsczH $)_{2}$ (2): To a roundbottom flask containing $0.7837 \mathrm{~g}(4.63 \mathrm{mmol})$ of furfuraldehyde thiosemicarbazone dissolved in $20 \mathrm{ml}$ dry methanol, $0.5434 \mathrm{~g}$ ( $2.58 \mathrm{mmol}) \mathrm{CoCl}_{2} \cdot 6 \mathrm{H}_{2} \mathrm{O}$ in methanol was added with constant stirring and stirring was continued for $24 \mathrm{~h}$. Then the solvent was evaporated in vacuo to get a brown solid. It was repeatedly washed with cyclohexane and n-hexane to remove any impurities present. It was dried under vacuum to get a free solid (yield: $0.9802 \mathrm{~g}, 91.67 \%$, M.P. $198^{\circ} \mathrm{C}$ ). Elemental analyses for $\mathrm{CoCl}_{2} \mathrm{C}_{12} \mathrm{H}_{14} \mathrm{~N}_{6} \mathrm{~S}_{2} \mathrm{O}_{2}$ (\%) found (calcd): Co 12.10 (12.58), C 30.60 (30.75), H 2.78 (2.99), N 17.65 (17.94), S 13.14 (13.67), Cl 15.28 (15.14); IR: $3384 \mathrm{~cm}^{-1}, 3270 \mathrm{~cm}^{-1}$ ( $v_{\mathrm{NH} 2}$ asym. and sym.), $3125 \mathrm{~cm}^{-1}\left(v_{\mathrm{N}-\mathrm{H}}\right), 1565 \mathrm{~cm}^{-1}\left(v_{\mathrm{C}-\mathrm{N}}\right), 1022 \mathrm{~cm}^{-1}\left(v_{\mathrm{C}-\mathrm{S}}\right)$; NMR ( $\delta$ in ppm) ${ }^{1} \mathrm{H}: 6.57-7.92\left(\mathrm{~m}, \mathrm{NH}_{2}+\mathrm{C}_{4} \mathrm{H}_{4}\right), 11.35(\mathrm{~s}$, $\mathrm{NH}),{ }^{13} \mathrm{C}: 180.39(\mathrm{C}=\mathrm{S}), 148.82(\mathrm{CH}=\mathrm{N}), 146.15,136.97$, 120.10, 114.00 (aromatic carbons).

2.2c Preparation of $\mathrm{Co}(\text { cinnamtscz })_{2}$ (3): To $0.6694 \mathrm{~g}$ (2.68 mmol) of $\mathrm{Co}(\mathrm{acac})_{2} \cdot 4 \mathrm{H}_{2} \mathrm{O}$, dissolved in $15 \mathrm{ml}$ dry methanol, $1.1166 \mathrm{~g}(5.43 \mathrm{mmol})$ of cinnamaldehyde thiosemicarbazone dissolved in $20 \mathrm{ml}$ dry methanol was added with constant stirring. The reaction mixture was refluxed for $8 \mathrm{~h}$. After the reaction was over, the solvent was evaporated under vacuum and the resulting brown solid was repeatedly washed with cyclohexane and n-hexane. The product obtained was dried in vacuo and weighed (yield: $1.025 \mathrm{~g}, 85.41 \%$, M.P. $215^{\circ} \mathrm{C}$ ). Elemental analyses for $\mathrm{CoC}_{20} \mathrm{H}_{20} \mathrm{~N}_{6} \mathrm{~S}_{2}$ (\%) found (calcd): Co 12.37 (12.60), C 52.01 (51.83), H 4.53 (4.27), N 18.23 (17.96), S 14.05 (13.68); IR: $3450 \mathrm{~cm}^{-1}, 3319 \mathrm{~cm}^{-1}\left(v_{\mathrm{NH} 2}\right.$ asym. and sym.), $1573 \mathrm{~cm}^{-1}\left(v_{\mathrm{C}-\mathrm{N}}\right), 1026 \mathrm{~cm}^{-1}\left(v_{\mathrm{C}-\mathrm{S}}\right)$; NMR $(\delta$ in ppm $){ }^{1} \mathrm{H}$ : 6.82-7.91 (m, $\left.\mathrm{NH}_{2}+\mathrm{C}_{6} \mathrm{H}_{5}-\mathrm{CH}=\mathrm{CH}-\mathrm{CH}=\mathrm{N}\right),{ }^{13} \mathrm{C}: 177.72$ $(\mathrm{C}=\mathrm{S}), 151.29(\mathrm{CH}=\mathrm{N}), 142.55,139.26(\mathrm{CH}=\mathrm{CH}), 129.46$, 127.72, 123.65, 121.15 (aromatic carbons).

2.2d Preparation of $\mathrm{CoCl}_{2}$ (cinnamtsczH) $)_{2}$ (4): To a round-bottom flask containing $0.7783 \mathrm{~g}(3.79 \mathrm{mmol})$ of cinnamaldehyde thiosemicarbazone dissolved in $20 \mathrm{ml}$ dry 
methanol, $0.4401 \mathrm{~g}(1.84 \mathrm{mmol}) \mathrm{CoCl}_{2} \cdot 6 \mathrm{H}_{2} \mathrm{O}$ in methanol was added with constant stirring and stirring was continued for $24 \mathrm{~h}$. Then the solvent was evaporated in vacuo to get a green solid. It was repeatedly washed with cyclohexane and n-hexane to remove any impurities present and then dried under vacuum to get free solid (yield: $0.6359 \mathrm{~g}, 62.87 \%$, M.P. $215^{\circ} \mathrm{C}$ ). Elemental analyses for $\mathrm{CoC}_{20} \mathrm{H}_{22} \mathrm{~N}_{6} \mathrm{~S}_{2} \mathrm{Cl}_{2}$ (\%) found (calcd): Co 11.11 (10.90), C 44.01 (44.40), $\mathrm{H}$ 4.53 (4.07), N 14.95 (15.04), S 11.32 (11.84), Cl 13.44 (13.11); IR: $3375 \mathrm{~cm}^{-1}, 3301 \mathrm{~cm}^{-1}\left(v_{\mathrm{NH} 2}\right.$ asym. and sym.), $3188 \mathrm{~cm}^{-1}\left(v_{\mathrm{N}-\mathrm{H}}\right), 1579 \mathrm{~cm}^{-1}\left(v_{\mathrm{C}-\mathrm{N}}\right), 989 \mathrm{~cm}^{-1}\left(v_{\mathrm{C}-\mathrm{S}}\right)$; NMR $(\delta$ in ppm $){ }^{1} \mathrm{H} 6.77-7.78\left(\mathrm{~m}, \mathrm{NH}_{2}+\mathrm{C}_{6} \mathrm{H}_{5}-\mathrm{CH}=\mathrm{CH}-\right.$ $\mathrm{CH}=\mathrm{N}), 11.01(\mathrm{~s}, \mathrm{NH}),{ }^{13} \mathrm{C}: 176.82(\mathrm{C}=\mathrm{S}), 145.59(\mathrm{CH}=\mathrm{N})$, $139.64,136.16(\mathrm{CH}=\mathrm{CH}), 129.52,128.47,127.56,125.46$ (aromatic carbons).

2.2e Preparation of Co(4-f-acphtscz $)_{2}$ (5): $\mathrm{Co}(\mathrm{acac})_{2} \cdot 4 \mathrm{H}_{2} \mathrm{O}$, $0.6699 \mathrm{~g}$ ( $2.68 \mathrm{mmol})$, was dissolved in $15 \mathrm{ml}$ dry methanol. To this, $1.1401 \mathrm{~g}(5.39 \mathrm{mmol})$ of 4-fluoro-acetophenone thiosemicarbazone dissolved in $25 \mathrm{ml}$ dry methanol was added with constant stirring and the reaction mixture was refluxed for $8 \mathrm{~h}$. After the reaction was over, the solvent was evaporated under vacuum and the resulting brown solid was repeatedly washed with cyclohexane and n-hexane. The product obtained was dried in vacuo and weighed (yield: $1.023 \mathrm{~g}, 79.39 \%$, M.P. $135^{\circ} \mathrm{C}$ ). Elemental analyses for $\mathrm{CoC}_{18} \mathrm{H}_{18} \mathrm{~N}_{6} \mathrm{~S}_{2} \mathrm{~F}_{2}$ (\%) found (calcd): Co 12.46 (12.29), C 45.34 (45.08), H 3.70 (3.78), N 17.20 (17.52), S 13.11 (13.37); IR: $3417 \mathrm{~cm}^{-1}, 3275 \mathrm{~cm}^{-1}\left(v_{\mathrm{NH} 2}\right.$ asym. and sym.), $1598 \mathrm{~cm}^{-1}\left(v_{\mathrm{C}-\mathrm{N}}\right), 1015 \mathrm{~cm}^{-1}\left(v_{\mathrm{C}-\mathrm{S}}\right)$; NMR $(\delta$ in ppm) ${ }^{1} \mathrm{H}: 6.82-7.91\left(\mathrm{~s}, \mathrm{NH}_{2}, \mathrm{~m}, \mathrm{C}_{6} \mathrm{H}_{5}-\mathrm{C}=\mathrm{N}\right),{ }^{13} \mathrm{C}: 177.73$ $(\mathrm{C}=\mathrm{S}), 142.89(\mathrm{CH}=\mathrm{N}), 134.53,130.39,129.154,127.80$ (aromatic carbons).

2.2f Preparation of $\mathrm{CoCl}_{2}(4-\mathrm{f} \text {-acphtsczH })_{2}$ (6): To a round-bottom flask containing $0.8040 \mathrm{~g}(3.80 \mathrm{mmol})$ of 4f-acetophenone thiosemicarbazone dissolved in $25 \mathrm{ml}$ dry methanol, $0.4456 \mathrm{~g}(1.87 \mathrm{mmol}) \mathrm{CoCl}_{2} \cdot 6 \mathrm{H}_{2} \mathrm{O}$ in methanol was added with constant stirring and stirring was continued for $24 \mathrm{~h}$. The solvent was evaporated in vacuo when a green solid was obtained. It was repeatedly washed with cyclohexane and $n$-hexane to remove any impurities present and then dried under vacuum to get free solid (yield: $0.9210 \mathrm{~g}, 89.07 \%$, M.P. $250^{\circ} \mathrm{C}$ ). Elemental analyses for $\mathrm{CoC}_{18} \mathrm{H}_{20} \mathrm{~N}_{6} \mathrm{~S}_{2} \mathrm{~F}_{2} \mathrm{Cl}_{2}$ (\%) found (calcd): Co 11.19 (10.66), C 39.25 (39.09), H 3.80 (3.61), N 15.06 (15.20), S 11.31 (11.50), Cl 13.15 (12.83); IR: $3437 \mathrm{~cm}^{-1}, 3304 \mathrm{~cm}^{-1}\left(v_{\mathrm{NH} 2}\right.$ asym. and sym.), $3146 \mathrm{~cm}^{-1}\left(v_{\mathrm{N}-\mathrm{H}}\right), 1598 \mathrm{~cm}^{-1}\left(v_{\mathrm{C}-\mathrm{N}}\right)$, $1011 \mathrm{~cm}^{-1}\left(v_{\mathrm{C}-\mathrm{S}}\right)$; NMR $\left(\delta\right.$ in ppm) ${ }^{1} \mathrm{H}: 7.138-8.215(\mathrm{~m}$, $\left.\mathrm{NH}_{2}+\mathrm{C}_{6} \mathrm{H}_{5}\right), 10.038(\mathrm{~s}, \mathrm{NH}){ }^{13} \mathrm{C}: 176.10(\mathrm{C}=\mathrm{S}), 148.05$ $(\mathrm{CH}=\mathrm{N}), 134.42,129.52,115.70,115.42$ (aromatic carbons).

\subsection{Thermal decomposition studies}

2.3a Pyrolysis in a furnace: Weighed quantities of each precursor $(\mathbf{1 - 6}, 350 \mathrm{mg})$ were taken in a quartz boat in a furnace. The furnace was heated to desired temperature under the flowing nitrogen atmosphere for $3 \mathrm{~h}$. After cooling the furnace, residue in quartz boat was taken out and further it was characterized by XRD, SEM, TEM, EDAX, UV-Vis, PL and Raman spectra.

2.3b Solvothermal decomposition in ethylene glycol: Cobalt sulphide nanoparticles were prepared by refluxing $0.250 \mathrm{~g}$ of the each precursor (1-6) in $20 \mathrm{ml}$ of ethylene glycol in $100 \mathrm{ml}$ round-bottom flask under nitrogen atmosphere for $3 \mathrm{~h}$. The colour of reaction mixture was changed to black. A viscous black solution with suspended particles was formed. After the decomposition is over the reaction mixture was brought to room temperature. The nanoparticles formed were separated by centrifugation. Most of the solid product was recovered by addition of methanol. The particles thus obtained were washed repeatedly with methanol and dried under vacuum. They were then characterized by XRD, SEM, TEM, EDAX, UV-Vis, PL and Raman spectra.

\section{Results and Discussion}

The precursors were prepared by reacting thiosemicarbazone ligands, $\mathrm{LH}$ ( $\mathrm{LH}=$ thiosemicarbazones of furfuraldehyde, cinnamaldehyde and 4-F-acetophenone) either with $\mathrm{Co}\left(\mathrm{OOCCH}_{3}\right)_{2} \cdot 4 \mathrm{H}_{2} \mathrm{O}$ or $\mathrm{CoCl}_{2} \cdot 6 \mathrm{H}_{2} \mathrm{O}$. The reactions of $\mathrm{Co}\left(\mathrm{OOCCH}_{3}\right)_{2} \cdot 4 \mathrm{H}_{2} \mathrm{O}$ with thiosemicarbazone ligands gave complexes of the type $\mathrm{CoL}_{2}$ (I) (equation 1). However, simple addition reaction of $\mathrm{CoCl}_{2} \cdot 6 \mathrm{H}_{2} \mathrm{O}$ with these ligands resulted in the formation of $\mathrm{CoCl}_{2}(\mathrm{LH})_{2}$ adducts (II) (equation 2).

$$
\begin{aligned}
& \mathrm{Co}\left(\mathrm{OOCCH}_{3}\right)_{2} \cdot 4 \mathrm{H}_{2} \mathrm{O}+2 \mathrm{LH} \frac{\text { Dry methanol, reflux }}{-2 \mathrm{CH}_{3} \mathrm{COOH},-4 \mathrm{H}_{2} \mathrm{O}} \mathrm{CoL}_{2} \\
& \mathrm{CoCl}_{2} \cdot 6 \mathrm{H}_{2} \mathrm{O}+2 \mathrm{LH} \stackrel{\text { Dry methanol, R.T. }}{-6 \mathrm{H}_{2} \mathrm{O}} \mathrm{CoCl}_{2}(\mathrm{LH})_{2}
\end{aligned}
$$

These compounds were characterized by elemental analysis, IR, NMR $\left({ }^{1} \mathrm{H}\right.$ and $\left.{ }^{13} \mathrm{C}\left\{{ }^{1} \mathrm{H}\right\}\right)$ spectroscopy. In the IR spectra, the bands observed in the range of $3400-3200 \mathrm{~cm}^{-1}$ are assigned to $\mathrm{NH}_{2}$ asymmetric and symmetric stretching modes. The $\mathrm{N}-\mathrm{H}$ stretching mode is observed in IR spectrum of (II). This mode is absent in the spectrum of precursors (I), indicating deprotonation of the ligand in the complexes. The bands due to $v_{\mathrm{C}-\mathrm{N}}$ and $v_{\mathrm{C}-\mathrm{S}}$ are observed at 1583 and $1013 \mathrm{~cm}^{-1}$ for precursors (I) and 1619 and $1022 \mathrm{~cm}^{-1}$ for precursors (II), respectively. The values are shifted to lower wavenumbers compared to those in the spectra of free ligands.

In the ${ }^{1} \mathrm{H}$ spectrum of precursors (II) signal due to proton of $-\mathrm{NH}$ group is observed. This peak is absent in the spectrum of precursors (I), showing deprotonation of $-\mathrm{NH}$ group during the reaction. These observations are consistent 


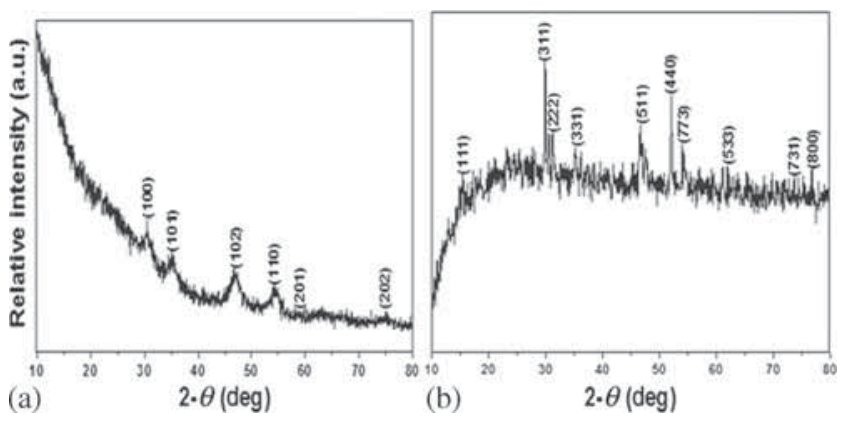

Figure 1. XRD patterns of (a) $\mathrm{CoS}$ and (b) $\mathrm{Co}_{9} \mathrm{~S}_{8}$ nanocrystallites obtained from pyrolysis of $\mathrm{Co}$ (furtscz) $)_{2}$ and $\mathrm{CoCl}_{2}$ (furtsczH $)_{2}$ in furnace at 450 and $475^{\circ} \mathrm{C}$, respectively.

with ligand coordination through azomethine nitrogen and sulphur atoms. The molar conductivity was measured for all the precursors (1-6) in DMF $\left(10^{-3} \mathrm{~mol} \mathrm{l}^{-1}\right)$. These values are $7.5(\mathbf{1}), 8.0(\mathbf{2}), 7.65(\mathbf{3}), 13.8(\mathbf{4}), 12.31$ (5) and 7.0 (6) $\Omega^{-1} \mathrm{~cm}^{2} \mathrm{~mol}^{-1}$, respectively. They are consistent with their non-electrolytic nature of the precursors. ${ }^{26}$

Pyrolysis of these complexes were carried out in furnace under nitrogen atmosphere. The black powder obtained was further characterized by powder XRD, SEM, TEM, SAED, UV-Vis, PL and Raman spectra. The pyrolysis of precursors (1) and (2) was carried out at 450 and $475^{\circ} \mathrm{C}$, respectively. In both the cases black residue was obtained. The XRD pattern revealed that the decomposition of precursor (1) results in the formation of hexagonal CoS (JCPDS: 75-0605; figure 1a) and that of the precursor (2) gave cubic $\mathrm{Co}_{9} \mathrm{~S}_{8}$ (JCPDS: 752023; figure 1b). No other diffraction peaks due to impurities were detected indicating that the synthesized product is pure. The average grain size $(D)$ was calculated using Scherer formula $D=0.89 \lambda / \beta \cos \theta$, where $\lambda=1.54060 \AA(\mathrm{CuK} \alpha)$ and $\beta$ is FWHM at the diffraction angle $\theta$. In the case of $\operatorname{CoS}$ calculated size is $7.0 \mathrm{~nm}$, whereas for $\mathrm{Co}_{9} \mathrm{~S}_{8}$ it is found to be $9.0 \mathrm{~nm}$. The decompositions of precursors (3) and (4) were carried out at 425 and $500^{\circ} \mathrm{C}$, respectively, whereas those of precursors (5) and (6) were carried out at $475^{\circ} \mathrm{C}$. From the XRD of the materials obtained from these precursors it is found that precursor (3) resulted into hexagonal $\mathrm{CoS}$ formation, whereas precursors (4), (5) and (6) resulted into formation of cubic $\mathrm{Co}_{9} \mathrm{~S}_{8}$ (supplementary figures $\mathrm{S} 1$ and S2).

The solvothermal decompositions of these precursors were carried out in ethylene glycol. Use of ethylene glycol like polyols can control the growth rate of crystal faces of metal sulphide (CoS) nanostructures and influence the oriented growth by interacting with these faces via adsorption and desorption reactions. ${ }^{27}$ This growth mechanism is similar to $\mathrm{CdS}$ nanostructures in ethylenediamine. ${ }^{28,29}$ Figure 2a shows XRD pattern of $\mathrm{Co}_{9} \mathrm{~S}_{8}$ (JCPDS: 75-2023) obtained from solvothermal decomposition of precursor (1) in ethylene glycol and figure $2 \mathrm{~b}$ shows XRD pattern of CoS (JCPDS: 75-0605) obtained from solvothermal decomposition of precursor (2) in ethylene glycol. The particle size calculated using Scherer formula is $4.0 \mathrm{~nm}$ for $\mathrm{Co}_{9} \mathrm{~S}_{8}$ and $10.0 \mathrm{~nm}$

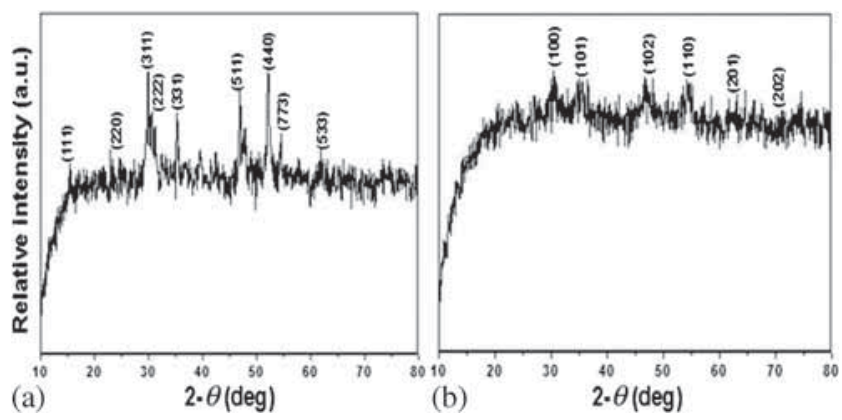

Figure 2. XRD patterns of (a) $\mathrm{Co}_{9} \mathrm{~S}_{8}$ and (b) $\mathrm{CoS}$ nanocrystallites obtained from solvothermal decomposition of $\mathrm{Co}$ (furtscz) $)_{2}$ and $\mathrm{CoCl}_{2}$ (furtsczH) $)_{2}$ in ethylene glycol, respectively.

for CoS. The solvothermal decomposition of remaining precursors, i.e., (3-6) resulted into the formation of hexagonal CoS (JCPDS: 75-0605; supplementary figures S3 and S4). The crystallite sizes calculated for these materials vary from 3 to $5 \mathrm{~nm}$.

The morphologies of the as-prepared materials were determined using SEM and TEM techniques. Figure $3 a$ and $b$ shows the SEM images of the materials obtained by pyrolysis of precursors (1) and (2), respectively, whereas figure 3c and d shows the EDAX spectra of the respective materials. SEM of the material obtained from precursor (1) shows the formation of flake-like morphology. Precursor (2) also gave material with the same morphology, but with smaller particle size. The EDAX analysis of both the materials matches with the 1:1 ratio of Co and S. The SEM images and EDAX spectra of the materials obtained by pyrolysis of precursors (3-6) are shown in supplementary figures S5 and S6. The morphology of the materials obtained is similar to the materials obtained from precursors (1) and (2). The EDAX analysis matches with the presence of 1:1 ratio of Co and $S$.

Figure 4 shows the SEM image and EDAX spectra of the materials obtained by solvothermal decomposition of precursors (1) and (2). The morphology of the materials obtained from these precursors is found to be nearly spherical particles. The EDAX analysis tentatively matches with 1:1 ratio between Co and S. The SEM images of the materials obtained by solvothermal decomposition of precursors (3-6) are given in supplementary figures S7 and S8. The morphologies of the materials are found to be flake like. The EDAX analysis of all these materials matches with 1:1 stoichiometries between $\mathrm{Co}$ and $\mathrm{S}$.

Figure 5 shows TEM images and SAED patterns of the nanocrystals obtained by pyrolysis of precursors (1) and (2), whereas supplementary figures S9 and S10 show TEM images and SAED patterns of the materials obtained from pyrolysis of precursors (3-6). The SAED pattern contains well-defined rings suggesting the presence of highly crystalline materials. In SAED pattern of CoS nanocrystallites, the measured spacing of the crystallographic planes are 0.291 and $0.168 \mathrm{~nm}$ corresponding to the two characteristics planes at 100 and 110 (figure 5c). The SAED pattern of $\mathrm{Co}_{9} \mathrm{~S}_{8}$ obtained from pyrolysis of precursor (2) shows 0.285 , 

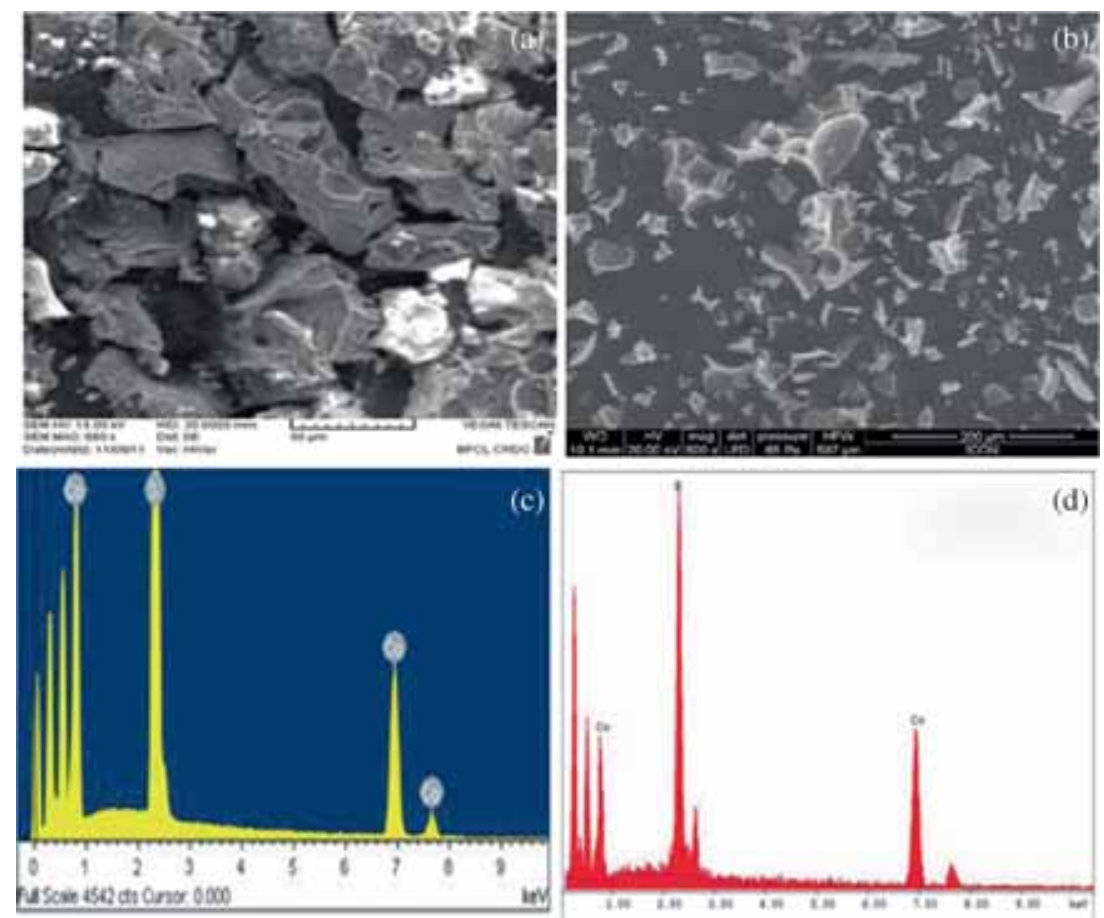

Figure 3. SEM images and EDAX spectra of (a, c) $\mathrm{CoS}$ and $(\mathbf{b}, \mathbf{d}) \mathrm{Co}_{9} \mathrm{~S}_{8}$ nanocrystallites obtained from pyrolysis of $\mathrm{Co}$ (furtscz $)_{2}$ and $\mathrm{CoCl}_{2}$ (furtsczH $)_{2}$ in furnace at 450 and $475^{\circ} \mathrm{C}$, respectively.

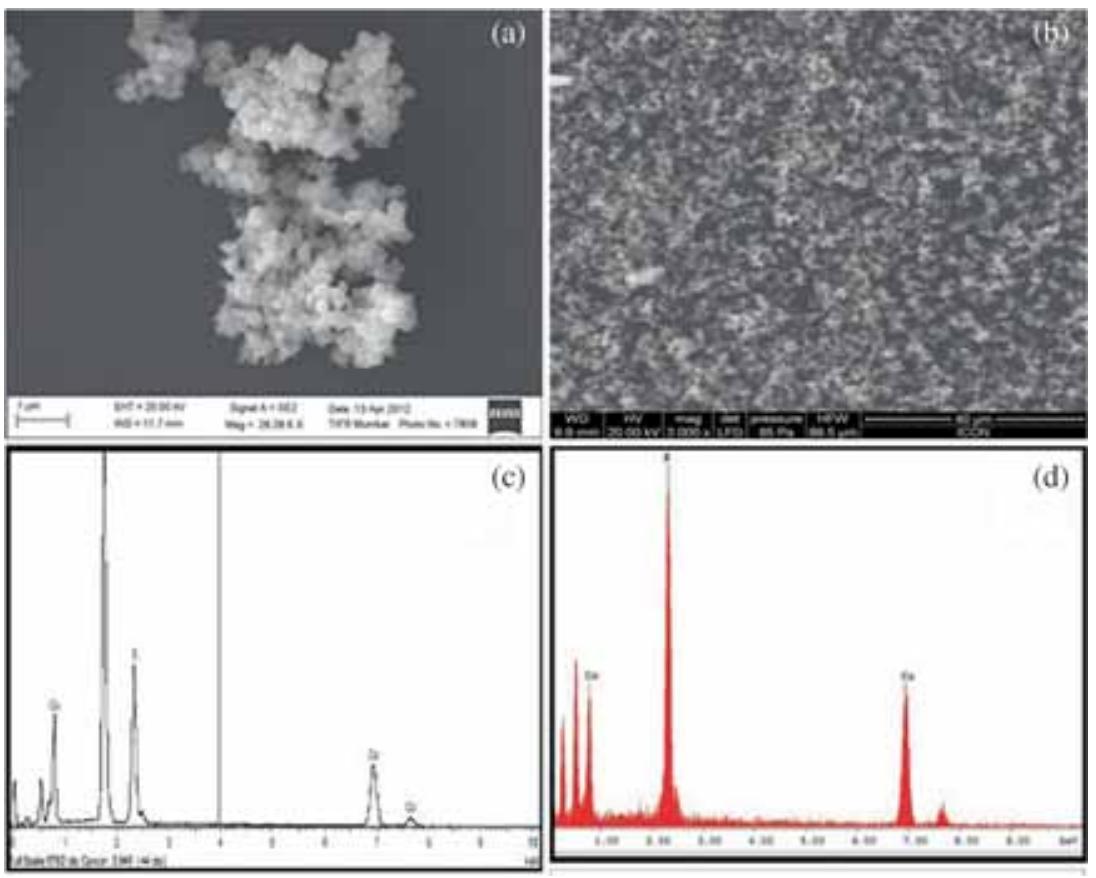

Figure 4. SEM images and EDAX spectra of $(\mathbf{a}, \mathbf{c}) \mathrm{Co}_{9} \mathrm{~S}_{8}$ and $(\mathbf{b}, \mathbf{d}) \mathrm{CoS}$ nanocrystallites obtained from solvothermal decomposition of $\mathrm{Co}$ (furtscz) $)_{2}$ and $\mathrm{CoCl}_{2}$ (furtsczH) in ethylene glycol, respectively.

0.190 and $0.175 \mathrm{~nm}$ d-spacings corresponding to 222,511 and 440 planes (figure $5 \mathrm{~d}$ ). The spherical shape morphology can be seen in TEM image. The TEM images for pyrolysis of precursors (4) and (6) show pyramidal and spherical shape morphology, respectively. (supplementary figures S9 and S10). 

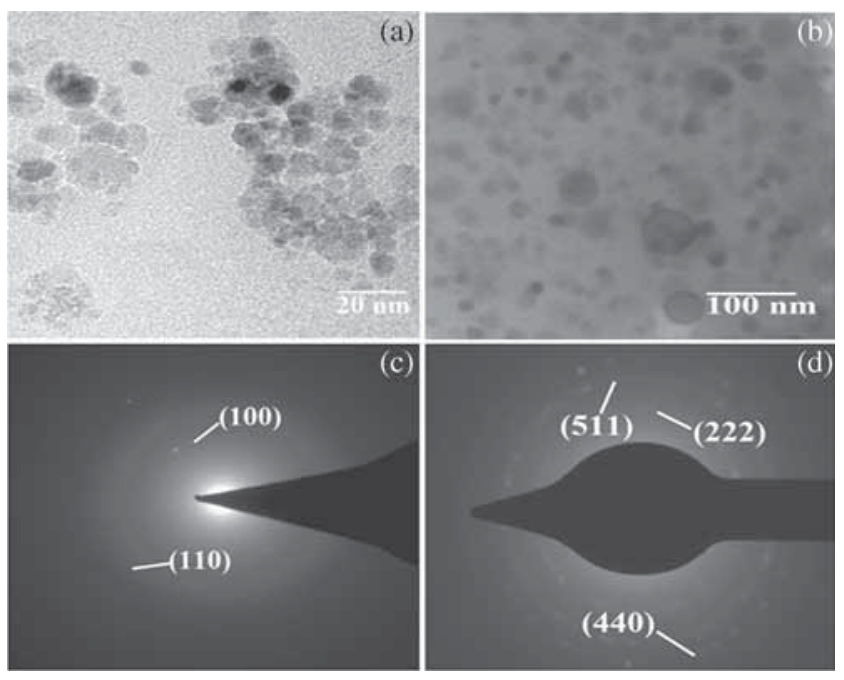

Figure 5. TEM images and SAED patterns of (a, c) CoS and (b, d) $\mathrm{Co}_{9} \mathrm{~S}_{8}$ nanocrystallites obtained from pyrolysis of $\mathrm{Co}$ (furtscz) and $\mathrm{CoCl}_{2}$ (furtsczH $)_{2}$ in furnace at 450 and $475^{\circ} \mathrm{C}$, respectively.

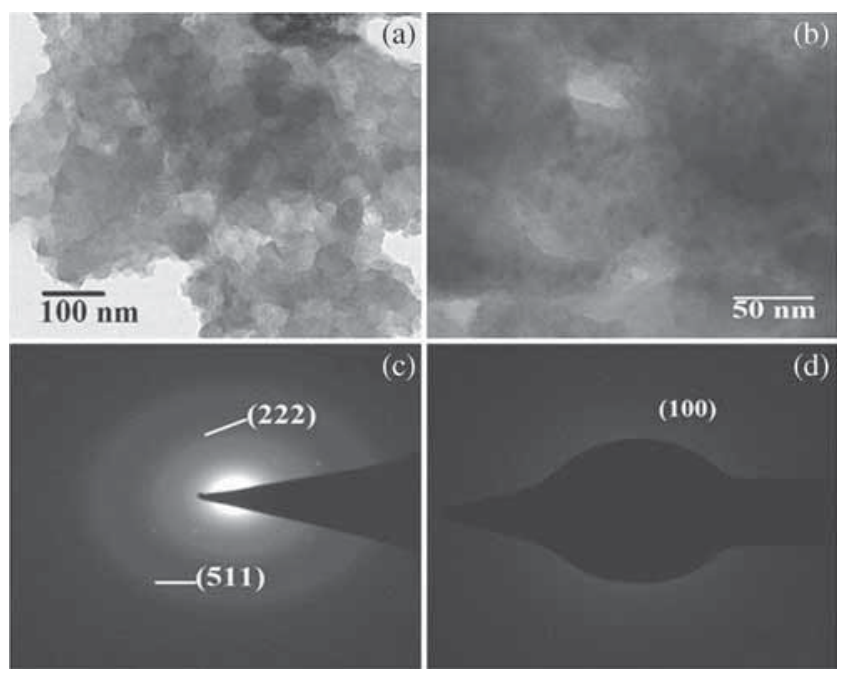

Figure 6. TEM images and SAED patterns of (a, c) $\mathrm{CoS}$ and (b, d) $\mathrm{Co}_{9} \mathrm{~S}_{8}$ nanocrystallites obtained from solvothermal decomposition of $\mathrm{Co}$ (furtscz) $)_{2}$ and $\mathrm{CoCl}_{2}$ (furtsczH) $)_{2}$ in ethylene glycol, respectively.

Figure 6 shows the TEM images of $\mathrm{CoS}$ and $\mathrm{Co}_{9} \mathrm{~S}_{8}$ nanoparticles obtained from the solvothermal decomposition of precursors (1) and (2). The spherical shape morphology can be seen in TEM image with agglomeration of nanoparticles. The SAED pattern of these nanocrystallites shows the amorphous nature. The TEM images of the materials obtained by solvothermal decomposition of precursors (3) and (4) show the formation of hollow sphere and cottonlike spherical shape morphology of these materials (supplementary figure S11). Supplementary figure S12 shows TEM images and the SAED patterns of the materials obtained from precursors (5) and (6). The formation of spongy morphology nanoparticles is observed in their TEM images. The rings

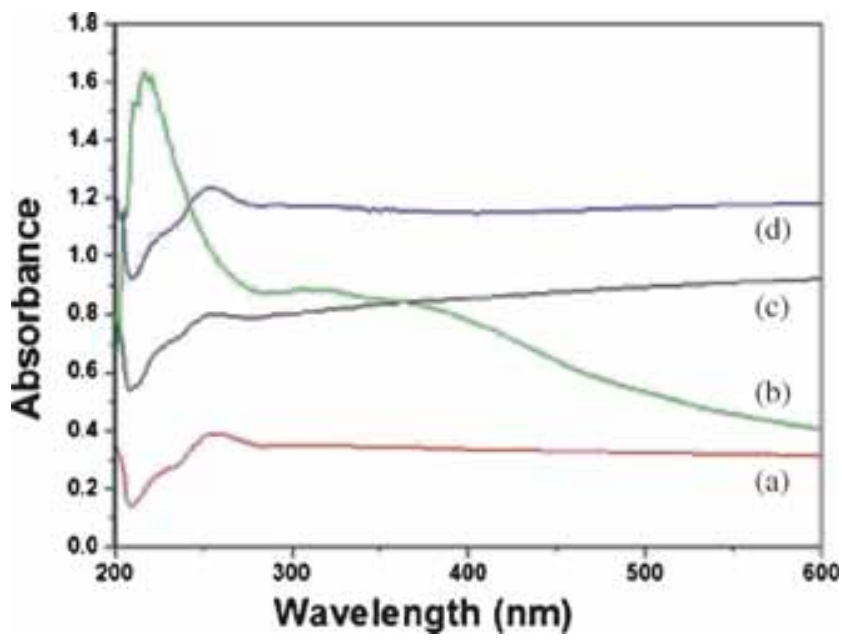

Figure 7. Absorption spectra of (a) $\mathrm{Co}_{9} \mathrm{~S}_{8}$ nanocrystallites obtained from pyrolysis of $\mathrm{CoCl}_{2}$ (furtsczH) $)_{2}$, (b) $\mathrm{CoS}$ nanocrystallites obtained from pyrolysis of $\mathrm{Co}(\text { cinnamtscz })_{2}$, (c) $\mathrm{CoS}$ nanocrystallites obtained from solvothermal decomposition of $\mathrm{CoCl}_{2}$ (furtsczH) $)_{2}$ and (d) $\mathrm{CoS}$ nanocrystallites obtained from solvothermal decomposition of $\mathrm{CoCl}_{2}$ (4-facphtsczH) 2 .

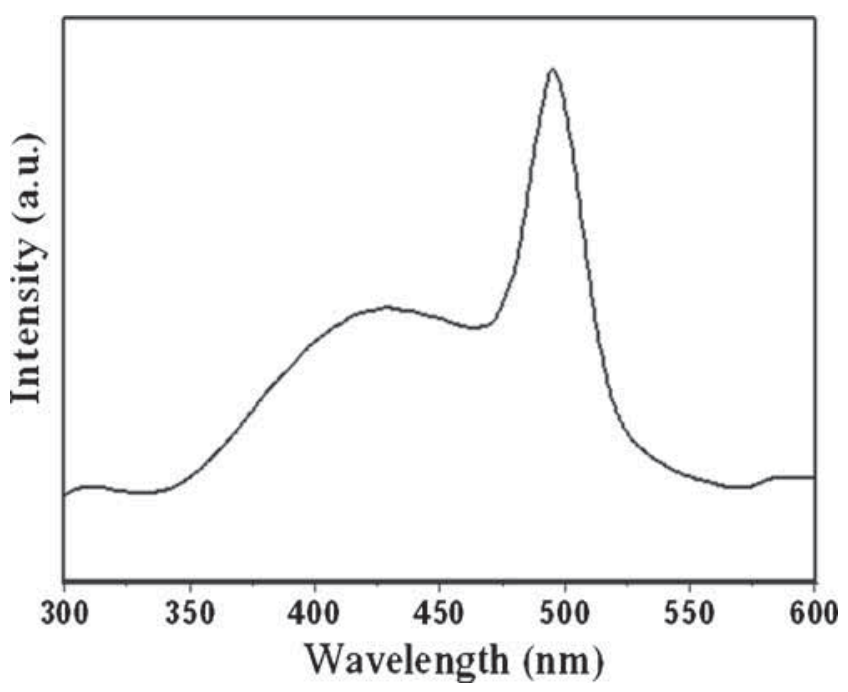

Figure 8. PL spectrum of $\mathrm{CoS}$ nanocrystallites obtained from solvothermal decomposition of $\mathrm{Co}(\text { cinnamtscz })_{2}$ in ethylene glycol.

present in the SAED patterns reveal crystalline nature of these materials.

UV-Vis absorption spectra of $\mathrm{Co}_{9} \mathrm{~S}_{8}$ and CoS nanocrystallites dispersed in methanol are shown in figure 7. Figure 7a and $b$ shows spectra for $\mathrm{Co}_{9} \mathrm{~S}_{8}$ obtained from the pyrolysis of precursor (2) and $\mathrm{CoS}$ obtained from precursor (3). Figure $7 \mathrm{c}$ and $\mathrm{d}$ shows spectra of the material $(\mathrm{CoS})$ obtained by solvothermal decomposition of precursors (2) and (6). In the absorption spectra of these materials, an absorption band at $251 \mathrm{~nm}$ is observed for $\mathrm{CoS}$ and $255 \mathrm{~nm}$ for $\mathrm{Co}_{9} \mathrm{~S}_{8}$ nanocrystallites, which are blue shifted as compared to bulk $\mathrm{CoS}$ which shows absorption band at $347 \mathrm{~nm}$. This indicates the formation of smaller particles. ${ }^{30}$ 


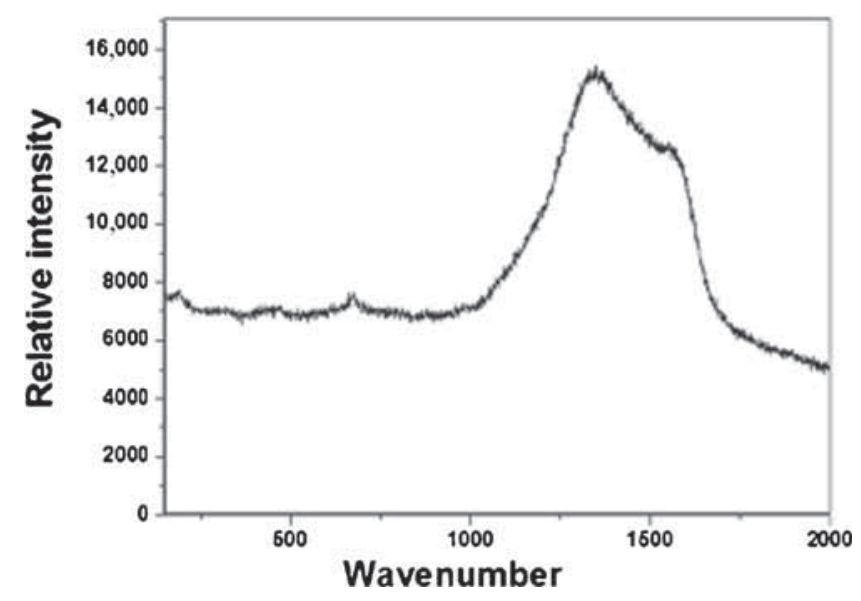

Figure 9. Raman spectrum of CoS nanocrystallites obtained from pyrolysis of $\mathrm{Co}(\text { furtscz })_{2}$ at $450^{\circ} \mathrm{C}$.

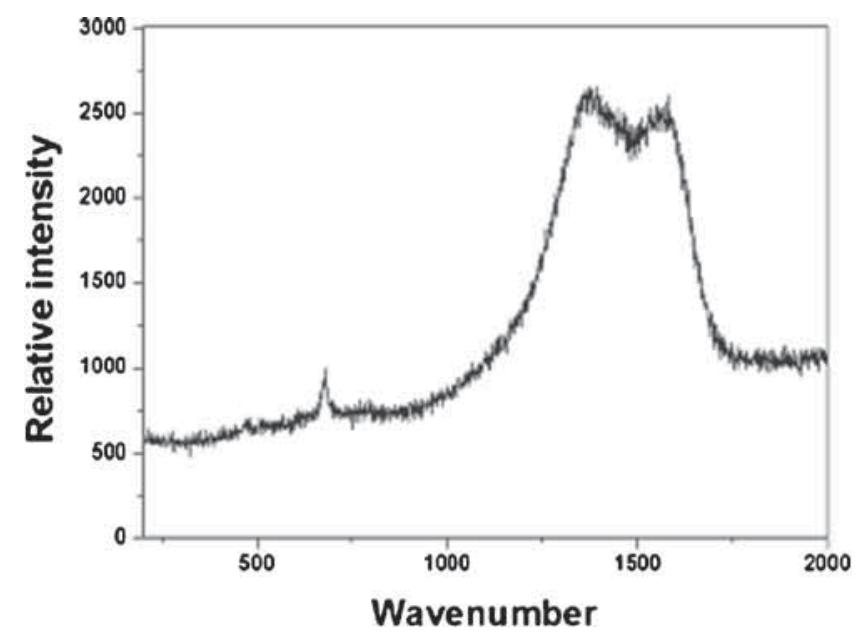

Figure 10. Raman spectrum of $\mathrm{CoS}$ nanocrystallites obtained from solvothermal decomposition of $\mathrm{CoCl}_{2}$ (furtsczH $)_{2}$ in ethylene glycol.

The representative photoluminescence spectrum of CoS nanocrystallites obtained from solvothermal decomposition of precursor 3 recorded at an excitation wavelength of $265 \mathrm{~nm}$ at room temperature is shown in figure 8. Cobalt is a transition metal impurity. It is a fast diffuser and gives rise to both radiative and nonradiative centres. ${ }^{31}$ The PL spectrum consists of two bands, of which one broad violet emission peak is observed at 423 and another at $495 \mathrm{~nm}$ for CoS nanocrystallites obtained from solvothermal of $\mathrm{Co}$ (cinnamtscz $)_{2}$. Bhattacharjee and $\mathrm{Lu}^{32}$ have reported $418 \mathrm{~nm}$ peaks to $\mathrm{S}^{2-}$ vacancy. ${ }^{32-34}$ Yanagida et $a l^{34}$ have observed defect-related longer wavelength luminescence at about $420 \mathrm{~nm}$. It has been reported that $423 \mathrm{~nm}$ peak has been classically termed as self-activated luminescence and known to be due to the recombination of carriers between $\mathrm{S}$ vacancy-related donor and valance band. The strong blue peak observed at $495 \mathrm{~nm}$ may arise due to native point defects.
Raman spectroscopy is an effective method to study the structures of the materials. The Raman spectra of CoS nanocrystallites obtained from pyrolysis of precursor (1) and solvothermal decomposition of precursor (2) show three well-resolved peaks at 675,1360 and $1560 \mathrm{~cm}^{-1}$ (figures 9 and 10). Similar Raman spectrum is observed for CoS nanocrystallites obtained from pyrolysis of precursor (3) (supplementary figure S13).

\section{Conclusions}

The hexagonal $(\mathrm{CoS})$ and cubic $\left(\mathrm{Co}_{9} \mathrm{~S}_{8}\right)$ cobalt sulphide nanocrystallites were obtained by simple pyrolysis and solvothermal decomposition routes using single-source precursors, $\mathrm{Co}(\mathrm{L})_{2}$ and $\mathrm{CoCl}_{2}(\mathrm{LH})_{2}$. The presence of nanocrystallites was confirmed by XRD, SEM, TEM, SAED, UV-Vis, PL and Raman spectral data.

\section{Acknowledgements}

ASP thanks DST-PURSE for financial support. Thanks are due to SAIF, IIT Bombay, for TEM and SAED patterns and TIFR, Mumbai, for providing SEM and EDAX data.

\section{Electronic Supplementary Material}

Supplementary material pertaining to this article is available on the Bulletin of Materials Science website (www.ias.ac.in/ matersci).

\section{References}

1. Schmid G 1994 Cluster and colloids (New York: VCH Press)

2. Furstner, A (ed) 1996 Active metals (Weinheim and New York: $\mathrm{VCH})$

3. Wang Y 1995 Adv. Photochem. 19179

4. Fenler J H and Meldrum E C 1997 J. Cluster Sci. 7607

5. Ozin G A 1992 Adv. Mater. 4612

6. Wells R L and Gladfelter W L 1997 J. Cluster Sci. 8217

7. Chow G M and Gonsalves K E 1996 Am. Chem. Soc. Symp. Ser. 622

8. Hu Q R, Wang S L, Zhang Y and Tang W H 2010 J. Alloys Compd. 498707

9. Wold A and Dwight K 1993 Solid State Chemistry (New York: Chapman and Hall Inc.)

10. Rao C N R and Pisharody K P R 1976 Prog. Solid State Chem. 10207

11. Wold A and Dwight K 1992 J. Solid State Chem. 9653

12. Pecararo T A and Chianelli R R 1981 J. Catal. 67430

13. Pathan H M and Lokhande C D 2004 Bull. Mater. Sci. 285

14. Morris B, Johnson V and Wold A 1967 J. Phys. Chem. Solid 281565

15. Smith G B, Ignatiev A and Zajac G 1980 J. Appl. Phys. 51 4186 
16. Whitney T M, Jiang J S, Searson P and Chien C 1993 Science 2611316

17. Yue G H, Yan P X, Fan X Y, Wang M X, Qu D M, Wu Z G, Li C and Yan D 2007 Electrochem. Solid State Lett. 1029

18. Feng Y G, He T and Vante N A 2008 Chem. Mater. 20 26

19. Chen X Y, Zhang Z J, Qiu Z G, Shi C W and Li X L 2007 J. Colloid Interface Sci. 308271

20. Chopra N G, Luyren R J, Cherry K, Crespi V H, Cohen V L, Louie S G and Zettle A 1995 Science 269966

21. Yang J, Liu Y C, Lin H M and Chen C C 2004 Adv. Mater. 16 713

22. Goldberger J, He R, Zhang Y, Lee S, Yan H, Choi H J and Yang P 2003 Nature 422599

23. Wirtz M and Martin C R 2003 Adv. Mater. 15455

24. Li Y D, Wang J W, Deng Z X, Wu X Y, Sun X M, Yu D P and Yang P D 2001 J. Am. Chem. Soc. 1239904
25. Wang Z H, Wang L L and Wang H 2008 Cryst. Growth Des. 8 4415

26. Geary W J 1971 Coord. Chem. Rev. 781

27. Hu Q R, Wang S L, Zhang Y and Tang H 2010 J. Alloys Compd. 491707

28. Wang Q, Gang X and Han G R 2005 J. Solid State Chem. 178 2680

29. Zhao Q T, Hou L S, Huang R A and Li S Z 2003 Inorg. Chem. Commun. 61459

30. Khaorapapong N, Ontam A and Ogawa M 2011 Appl. Clay Sci. 51182

31. Pal D and Bose D N 1994 Bull. Mater. Sci. 20401

32. Bhattacharjee B and Lu C H 2006 Thin Solid films 514132

33. Yang F, Wilkinson M, Austin E J and O'Donnel K P 1993 Phys. Rev. Lett. 70323

34. Yanagida S, Yoshida M, Shiragami T, Pac C, Mori H and Fujita H 1990 J. Phys. Chem. 943104 